\title{
Educação e ensino: Intenções, caminhos do professor e formação continuada como parte integrante da prática docente.
}

(Education and teaching: Intentions, teacher's path and continued training as an integral part of teaching practice.)

\author{
Maria Tavares de Oliveira \\ Secretaria Municipal de Piraquara, Paraná-Brasil \\ Camile Vieira Lourenço \\ Secretaria Municipal, Curitiba, Paraná- Brasil \\ Beatriz Ribeiro do Prado Carneiro \\ Secretaria Estadual de Educação do Paraná, Curitiba Paraná-Brasil
}

Fecha recepción: 21-08-2018

Páginas 37-48

Fecha aceptación: 30-09-2018

\section{Resumo.}

Esta pesquisa teve por objetivo apontar as considerações mais relevantes quanto a formação continuada para a prática docente no ensino fundamental I. O estudo discutiu os aspectos mais importantes para um ambiente de aprendizagem e as formas que se executa a função educativa numa perspectiva qualitativa que possa amenizar aos desafios enfrentados pelos docentes em sala de aula. $O$ estudo se utilizou do método qualitativo do tipo descritivo. Pesquisou-se a totalidade da população 07 docentes de forma intencional dirigida a todos os docentes efetivos da Escola Rural Municipal Bernhard Julg. Os instrumentos utilizados o questionário e a entrevista. Por fim, pode-se dizer que a formação continuada contribui sim de forma positiva para a melhoria do processo desde a ação didática pedagógica, motivação, liderança, autonomia, relações interpessoais para um ensino mais democrático.

Palavras-chave: gestão; formação; prática; docente; ensino básico

\section{Abstract.}

This research had the objective of pointing out the most relevant considerations regarding the continuous training for the teaching practice in elementary education I. The study discussed the most important aspects for a learning environment and the forms that the educational function is executed in a qualitative perspective that can soften to the challenges faced by teachers in the classroom. The study was based on the descriptive type qualitative method. The totality of the population was investigated intentionally 07 directed to all the effective teachers of the Municipal Rural School Bernhard Julg. The instruments used the questionnaire and the interview. Finally, it can be said that continuing education contributes positively to the improvement of the process from pedagogical didactic action, motivation, leadership, autonomy, interpersonal relationships to a more democratic teaching.

Keywords: management; formation; practice; teacher; basic education 


\section{1.-Introdução.}

A gestão escolar contribui para ampliação do conhecimentos dos professores e fundamentalmente para se analisar as condições existentes na escola, ela não compõe, também não serve para consolidar e alargar um conhecimento especializado sobre a dinâmica existentes na escola. Por meio da leitura e reflexão de vários autores, é possível identificar subsídios para o trabalho educativo, tornando possível uma educação transformadora.

É preciso muita intencionalidade para provocar mudanças no processo de produção do conhecimento e ter em mente que a educação básica deve estar alicerçada nas múltiplas necessidades humanas. Trata-se de um processo articulador das relações sociais, culturais e educacionais que na sala de aula tem como foco de maior atenção os professores Barbieri (1995).

Ensinar é a função mais nobre da educação escolar, depende do lugar chamado escola, Aristóteles propôs que se ensinasse o diálogo, Sócrates provou que a virtude depende da sabedoria, talvez o futuro nos reserve um ateneu virtual, mas não podemos abrir mão do espaço de aprendizagem e do diálogo, tão antigo para os educadores quanto a própria educação que pode ser compreendida como 0 ato de ensinar em sala de aula Sacristán (1998).

Diante do intenso ritmo de mudanças na sociedade, tem-se a necessidade constante de atualização e reflexão, de muitas vezes adotar formas criativas de ensinar e de se relacionar melhor com os alunos, estes são alguns desafios que os professores enfrentam, diante o referencial escolar neste novo século Cortela (2002).

A intenção de aprofundar a análise sobre a formação continuada e o cotidiano profissional do professor na construção de sua docência, assim como, tornar a sala de aula um espaço de troca e de construção efetiva de conhecimento. E como melhorar quando o professor se sente esgotado e desmotivado? Como fazer para os alunos estudarem? E como os professores podem ensinar de fato? Será que os professores pensam que ensinam e os alunos pensam que aprendem? essas são questões recorrentes no ambiente escolar Morim (2005).

Assim sendo, a partir do problema o desafio do professor do ensino básico o objetivo que busca apontar sugerir habilidades a serem tratadas na formações continuadas se estas contribuem diante dessas dificuldades da prática pedagógica, da palavra ao uso do computador esse referencial enfoca nesse contexto, elementos significativos a ação didática, a formação e as relações sociais do professor $x$ alunos $x$ escola, onde o processo educativo e a escola se concentram e estão situadas dentro desta ação, que é coletiva Candu (2001).

\section{2.-Pedagogia e a arte de ensinar.}

Sabe se que, a mudança de comportamento de visão de mundo acontece na vida escolar, e tira os educandos da zona de conforto, forçando-os a fazer as coisas de 
modo diferente, o que é complicado de se pensar na atuação e compromissos do professor do ensino básico, já que muitas vezes é difícil para o professor desenvolver este senso crítico nos alunos Assim, quando as ideias são desafiadas, torna-se importante repensar e refletir a posição e a prática, e as ações das pesquisadoras sobre este tema, e é sempre desconfortável, mas, motivador.

Os relacionamentos e os conflitos estão presentes nas relações interpessoais do ser humano, eles são um dos focos de estudo de pesquisas sobre 0 ato de ensinar. Um deles é a habilidade de liderança de influenciar pessoas para trabalhar entusiasticamente que vise atingir os objetivos identificados para o bem comum. Existem duas dinâmicas em jogo: a prática docente e os relacionamentos em sala de aula e na escola. "Todos deixam sua marca na equipe, a única questão é que tipo de marcante cada um quer deixar" (Hunter, 2006, p. 23).

Então questiona-se, como educadores podem mudar as práticas de ensino, para criar marcas permanentes aprendizagem dos alunos, a capacidade de liderança pode auxiliar neste processo? O professor também pode assumir o compromisso de liderar, para que isso seja possível é preciso que professor tenha um bom conhecimento de relações interpessoais, sabendo dessa forma lidar com várias situações e auxiliar na resolução de problemas. Todos são responsáveis pelo êxito de seus alunos, do grupo e também do resultado que se possam alcançar, este foco é importante na pesquisa, pois, liderança é uma profunda interferência na vida de outras pessoas. E uma habilidade, isto é, uma capacidade aprendida ou adquirida por meio da educação, da sua aplicação, vontade e intenção de mudar e contribuir para o sucesso dos membros da escola e do projeto político pedagógico, cuja função faz parte da gestão escolar pedagógica Lima (2003, p 54).

O propósito do referencial é o de acreditar, ser importante, motivador e estar em sintonia com os objetivos da escola básica, voltado para o professor e sua prática, se torna uma realidade, um desafio considerável na capacitação profissional desse educador para que se cumpra a função educativa faz se necessário, que o professor tenha condições efetivas na sua prática, que sejam reforçados os fundamentos que norteiam sua ação e suas relações interpessoais, com mais determinação, competência, preparo profissional e com participação para oferecer aos alunos condições de se tornarem sujeitos de sua própria história Sacristán (1998,p. 44).

A prática depende do caráter e da visão que se tem da escola e como 0 trabalho pedagógico será feito. A transformação será construída através da ética, justiça, da igualdade e do conhecimento. Essa busca estará voltada à perspectiva emancipadora do professor, de uma pedagogia, da autonomia, onde se insere a escola no processo de produção humana. Resgata-se nessa busca, a responsabilidade coletiva e 0 papel do pedagogo, que tem aqui seu caráter e responsabilidade na formação do professor e este na formação humana na sala de aula, onde o conhecimento é produzido e está presente. Há que se encontrar novamente o encantamento sensibilidade, e resgatar através do papel de líder, este profissional da educação, hoje tão desgastados, mas com ideias inabaláveis Freire, $(1979$, p. 33). 
São desafiadoras as tarefas do pedagogo, no momento atual, de se lançar na conquista dessas perspectivas. Há necessidade de encontrar suas funções sociopolíticas e pedagógicas, e também trabalhar de forma interativa 0 ato da prática escolar, realizando desta forma, um processo dinâmico no qual está inserido, com base no estudo efetuado, salientar a importância das habilidades citadas, da complementação teórica e das intervenções realizadas no desenvolvimento deste trabalho, os principais benefícios que o professor poderá obter são:

- Aproveitamento de tempo;

- Boa comunicação;

- Capacidade de liderança;

- Melhor inter-relação;

- Criatividade expandida;

- Aplicação de procedimentos significativos;

- Concretização dos valores éticos e morais;

- Melhor desenvolvimento profissional;

- Motivação e entusiasmo para o trabalho;

- Desenvolvimento de potencialidades;

- Co responsabilidade;

- Solidariedade;

- $\quad$ Troca de experiências Demo (1993, p. 65).

As atividades de estudos de textos e o levantamento teórico são desenvolvidos por meio de reflexões, a fim de compreender como ocorre a ação docente e assim pôde analisar a relação entre a proposta didática usada e a aprendizagem a ser conquistada para poder oferecer intervenções adequadas a cada situação, a intenção é favorecer a ação do professor; propiciar, a aprendizagem e 0 melhoramento da prática, como contribuição para a construção de uma escola aberta à diversidade individual, cultural e social que, culmine em condições propícias para a aprendizagem de todos e também na eficácia do trabalho do professor do ensino básico Wachowicz (1998, p. 78).

Os anos 90, testemunha uma crescente consolidação dos valores democráticos, fruto das lutas travadas politicamente, com a participação da sociedade civil organizada, mesmo assim, a área educacional ainda enfrenta sérios desafios, a partir do próprio conceito de educação e da finalidade de harmonização quantitativo e o qualitativo.

Outro desafio ao desenvolvimento do processo educativo está nos modelos de gestão. Isto é, apesar dos esforços para evolução da gestão centralizada, burocrática e autoritária, para a compartilhada que contribua para autonomia da escola, professores e alunos, a melhoria da qualidade de aprendizagem, da participação e da formação geral deve representar o eixo central das mudanças, ao longo do século XXI, com profundo sentido ético, fundamental neste tempo de rápidas mudanças e no qual participa Demo (1993, p. 76). 
Ser professor hoje em dia é uma "missão quase impossível". É preciso ter jogo de cintura para enfrentar as diversas contradições e conflitos, como por exemplo: muitos alunos veem a escola como um lugar de lazer, e não necessariamente um vão a escola para aprender, para esses alunos a escola é o local para se divertir e encontrar os amigos, esse fator contribui para que conflitos nascem, esses conflitos aparecem quando o professor explica algo que não é compreendido, ainda tranquilo, e com outras palavras, ele explica de novo, e outra vez sem sucesso, rapidamente então ele vai considerar 0 aluno incapaz.

O professor culpa o aluno, mas muitas vezes se sente fracassado porque sua turma não avança, não aprende, 0 aluno por sua vez, pensa que 0 professor não sabe ensinar, o clima fica tenso e um motivo sem importância serve de fator desencadeante para uma agressão verbal ou até física, então, é necessário rever a ação pedagógica, em constante mudança e desgastada profissionalmente Sacristán (1998, p.87).

Alguns questionamentos são apontados como propulsores de novas bases para 0 avanço da formação de professores. Em evidência, a atuação deles em sala de aula, muitas vezes, na escola, participam por meio da educação sistematizada, onde ainda se volta para a divisão social do trabalho: objetiva prover 0 aluno de elementos culturais necessários para viver na sociedade a que pertence. É importante que se coloque no centro das discussões e das práticas a função educativa global da escola e, verificar para quem ensina. Cabe ao professor criar condições criativas e transformar a situação de ensinar Wachowicz (1989, p. 79).

No que se refere à aprendizagem o professor deve compreender em quais situações, um aluno aprende e em qual não aprende, e como garantir sucesso escolar a todos no que diz respeito ao ensino básico? Profissionais da educação têm como objetivo principal promover o desenvolvimento integral do aluno, no sentido de torná-lo sujeito de sua própria história, mas, para que isso aconteça, é necessária a busca constante de atualização, de metodologias, técnicas, recursos de ensinos e de habilidades condizentes com a atual realidade de nossas escolas, por este motivo a formação continuada é uma importante ferramenta para que o professor tenha condições de atuar na escola de hoje e na de amanhã.

Há que se rever os condicionamentos históricos produzidos na escola, que vem colocar o ensino como processo reprodutor de um saber parcelado que muito tem refletido nas relações de tratamento e na predominância da desvinculação do conhecimento, do projeto global da educação e da sociedade. O professor ainda se julga dono dos saberes; o aluno receptivo, objeto ou sem mínimo de interesse; as relações de posições estabelecidas, isso sem falar na homogeneidade enraizada nas práticas pedagógicas descompromissadas. Uma das tarefas do professor é fazer nascer novas questões e 0 interesse pela escola, pelos saberes; rever atitudes, 0 próprio planejamento das atividades e dos conteúdos e também as formas de avaliação. Caso contrário, ele gasta o ano letivo em embates sem soluções. Assim, quando faltam reflexão no saber, prazer e aventura na sala de aula, a escola perde 0 seu sentido original, que se refere ao saber propriamente dito Shor (1986, p. 87). 
Segundo Gandin (2000) "Planejamento deve alcançar só que se façam bem as coisas que se fazem (chamaremos isso de eficiência), mas que façam as coisas que realmente importa fazer, porque são socialmente desejadas (chamaremos a isso de eficácia)".

Neste contexto, os profissionais da educação são desafiados constantemente ao desconhecido, e a renovação de suas práticas educacionais, torna uma questão de sobrevivência da escola, entretanto esta renovação é complexa, pois é necessário se passar pelos aspectos da prática em sala de aula, além da abertura dos que estão envolvidos no processo com vontade política de mudar, os meios para concretizar essas aspirações devem estar em consonância com o contexto histórico concreto, isso poderá ser possível pela compreensão e aplicação de uma autonomia a ser construída coletivamente e também articulada com o universo mais amplo da escola, conforme defende Cortela (2002), um amanhã sobre o qual não possuímos certezas, mas sabemos possibilidades. A presença desse modelo de gestão pode estar a intensificar o padrão de autonomia que deverá ser construído.

Para ganhar consistência e ser um referencial para os professores do ensino básico, na reflexão e aquisição de habilidades, estes, devem buscar por meio de diferentes estudiosos, subsídios necessários, que fornecerão elementos significativos para prosseguir na prática e na pesquisa, estudos e tendências indicam que é preciso reconhecer que professor es não possuem apenas saberes, mas também competências profissionais que não se reduzem ao domínio do conteúdo a ser ensinado, e também aceitar a ideia de que a evolução exige que todos possuam competências antes reservadas aos inovadores ou àqueles que precisavam lidar com um determinado tipo de aluno com características Candau (2001, p. 89).

Atualmente existe um referencial que identifica cerca de 50 competências na profissão docente, algumas delas são novas ou adquiriram uma crescente importância nos dias de hoje em função das transformações dos sistemas educativos, bem como da profissão e das condições de trabalho do professor.

Perrenoud (2001), afirma que essas competências dividem-se em dez grandes áreas, com vários tipos de conhecimentos:

- Organizar e estimular situações de aprendizagem.

- Gerar a progressão das aprendizagens.

- Conceber e fazer com que os dispositivos de diferenciação evoluam.

- Envolver os alunos em suas aprendizagens e no trabalho.

- Trabalhar em equipe.

- Participar da gestão da escola.

- Informar e envolver os pais.

- Utilizar novas tecnologias.

- Enfrentar os deveres e os dilemas éticos da profissão.

- Gerar sua própria formação contínua. 
É importante ter em mente que, quando se busca uma nova organização do trabalho pedagógico dentro da escola, considera-se que as relações de trabalho devem estar apoiadas em atitudes de solidariedade, de respeito, de reciprocidade e de participação coletiva e não em fragmentos ou divisões, então, uma nova gestão escolar, deve visar novas formas de relações de trabalho, no interior da escola, com espaços abertos à reflexão coletiva que venha favorecer o diálogo, a comunicação entre todos os envolvidos no processo educativo, o que irá contribuir para que novas relações sejam construídas na dinâmica interna da sala de aula e na escola (Morim, 2005, p. 87).

\section{3.-As práticas pedagógicas e a difícil tarefa de ensinar.}

A competência de ser professor é algo que dificilmente se ensina, mas que facilmente se aprende quando o professor, é um profissional que aceitou desempenhar a função de educar e que se comprometeu em criar condições para que os outros aprendam, esta competência não é estática e sim, dinâmica, principalmente se 0 professor souber estar atento aos desafios do cotidiano e fazer dele um contexto de qualificação e atualização permanente e assim sua prática se converterá em experiência refletida, vivida e praticada.

Quando o professor tem formação universitária, é esperado que este seja capaz aprender a partir da experiência, de refletir e formar na prática as competências sem as quais não poderiam sobreviver em uma sala de aula, embora não garanta uma prática reflexiva, um elevado nível de formação predispõe a ela, o problema é que cada um aprende por si mesmo, sem imaginar que muitas vezes chega, por meio de caminhos incertos e difíceis, às aquisições das ciências sociais e humanas e às habilidades do professor, portanto 0 que se deve proceder é uma transposição didática a partir das práticas reais. Reequilibrar os programas de formação de professores, articular as competências identificadas com uma verdadeira cultura básica na educação e desenvolvê-las em função, de um procedimento reflexivo de atuação baseada na realidade das práticas docentes Lima (2003, p. 32).

Compreender a natureza da escola e da atividade docente nessa perspectiva implica articular a aprendizagem do aluno à formação continuada do professor, e, como afirma Lima, compreender que a formação contínua deve estar:

"A serviço da reflexão e da produção de um conhecimento sistematizado, que possa oferecer a fundamentação teórica necessária para a articulação com a prática criativa do professor em relação ao aluno, à escola e à sociedade" Lima (2001, p. 32).

A formação continuada é a articulação entre o trabalho docente, o conhecimento e 0 desenvolvimento profissional do professor, como possibilidade de postura reflexiva dinamizada pela práxis, e de que a formação continuada não pode se efetivar se não estiver conectada com os sonhos, a vida e o trabalho do professor (Lima, 2001, p. 65). 
Para realizar seu trabalho docente é preciso que o professor se aproprie constantemente dos avanços das ciências e das teorias pedagógicas, há ainda, uma razão muito mais premente e mais profunda, como apontam os autores Barbieri, Carvalho e Ulhe (1995), que a própria natureza do fazer pedagógico, que faz parte da práxis e portanto histórico e inacabado.

O processo educativo é uma experiência extremamente complexa e que não diz respeito somente à sala de aula e, mesmo nela, não está somente no que 0 professor fala e o aluno ouve, como sabemos, existe todo um conjunto de atitudes, fatos, vivências, experiências pessoais, habilidades, competências, interesses, vontades, relações, concepções de vida e de mundo e toda uma vida escolar que sem dúvida alguma, determinará a cada aluno e professor, graus diferentes a qualidade de sua formação e atuação.

São muitos os avanços e as contribuições teóricas que permitem desenvolver ações que levem em conta um professor inserido em um contexto sócio histórico, que tem como função transmitir o conhecimento socialmente acumulado, em uma perspectiva transformadora da realidade, para tanto, é fundamental que se tenham claros os conceitos, as ideias e as concepções que orientam as ações do professor e que estes encarem as contribuições teóricas como subsídios que possibilitam a reflexão sobre a prática, e não a solução final para todos os problemas de forma predominante e definitiva.

\section{3.-Metodologia.}

A pesquisa se utilizou do método qualitativo do tipo descritivo. Segundo Miranda (2010), a pesquisa se realiza no ambiente natural onde se encontram os fenômenos estudados.

As investigações qualitativas Miranda (2010) coloca que se realiza com número reduzido de casos, mas em profundidade abrange todos os aspectos psicossociais que possam afetar a conduta humana dos casos estudados.

A amostra foi intencional dirigida a toda a população 07 (sete) docentes do Ensino Fundamental I, efetivos da Escola Rural Municipal Bernhard Julg.

Os instrumentos utilizados para a coleta de dados foram o questionário fechado e uma entrevista estruturada fundamentado nas revisões bibliográficas.

\section{4.-Discussão dos Resultados.}

Pesquisa buscou saber mais sobre a relação da formação continuada e a prática docente. Para isso se pesquisou de forma intencional dirigida toda a população docente (07) docentes efetivos da escola Rural Municipal Bernhard Julg do Ensino Fundamental I, mantendo o sigilo dos nomes conforme conselho de ética.

Profa $.1^{\circ}$ anoF1. L.2017;

Profa $1^{0}$ anoF1. E.2017;

Profa $^{2} 2^{0}$ anoF1. E.2017; 
Profa $2^{\circ}$ anoFB. P.2016;

Profa $.3^{\circ}$ anoF1. M.2017;

Profa $4^{0}$ anoF1. A.2017;

Profa $.5^{\circ}$ anoF1. V.2014.

A pesquisa por meio de questionários fechado, utilizando dois instrumentos, $01^{0}$ instrumento de forma ampla, o $2^{\circ}$ instrumento questionado em 12 aspectos importantes, que a formação pedagógica continuada, contribui para a prática do professor em sala de aula.

- Sobre a formação continuada na área pedagógica, $100 \%$ dos professores do $5^{0}$ ano do Ensino Fundamental I, tem buscado constantemente 0 aperfeiçoamento profissional.

No que se refere aos benefícios e ou contribuição quanto a formação teórica continuada para a prática docente foram analisados 12 itens:

1. Aproveitamento de tempo;

2. Boa comunicação;

3. Capacidade de liderança;

4. Favorecimento para a aplicação de procedimentos significativos;

5. Melhor inter-relação;

6. Criatividade expandida;

7. Concretização dos valores éticos e morais;

8. Melhor desenvolvimento profissional;

9. Motivação e entusiasmo para o trabalho;

10. Desenvolvimento de potencialidades;

11. Corresponsabilidade;

12. Solidariedade;

Gráfico 1: Quanto ao aproveitamento de tempo?

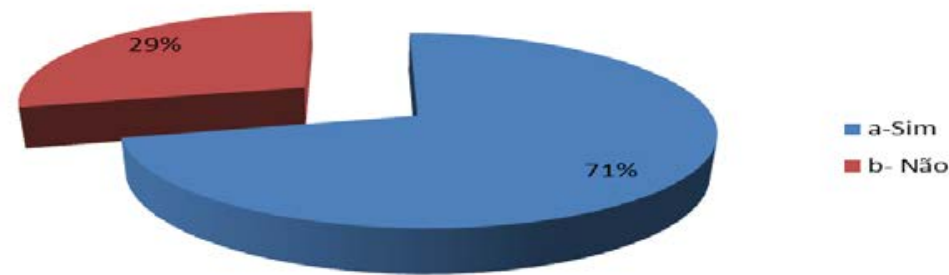

Fonte: dados da pesquisa.

O gráfico 1: mostra que $71 \%$ dos professores concordam que a formação continuada contribui o aproveitamento de tempo. No entanto, 29\% disseram que a formação não contribui pois está depende da didática docente para o ensino aprendizagem.

Gráfico 2: Quanto a boa comunicação? 


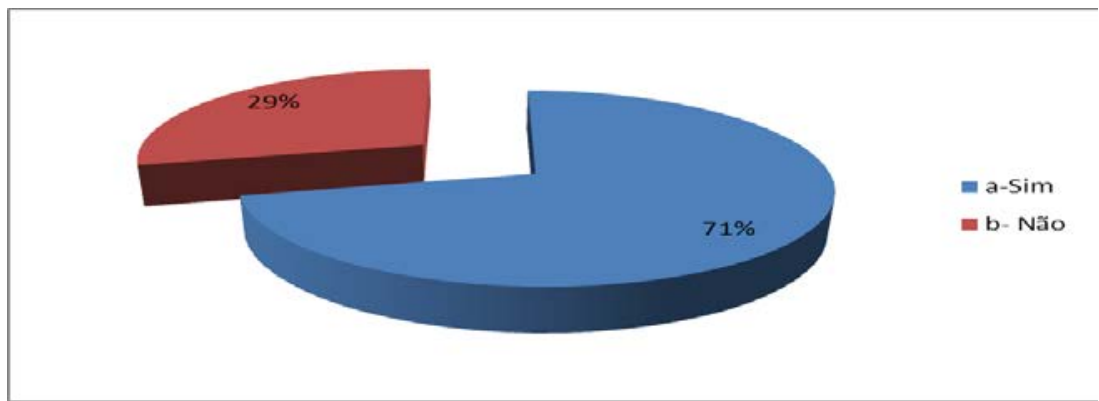

Fonte: A própria pesquisa.

Gráfico 2: aponta que $71 \%$ dos professores colocaram que a formação continuada contribui para uma boa comunicação Uma vez que nestas formações os docentes invertem os papéis dentro da dinâmica do ensinar e aprender contudo, 29\% professores responderam que a formação não favorece para uma boa comunicação.

Gráfico 3: Quanto a capacidade de liderança?

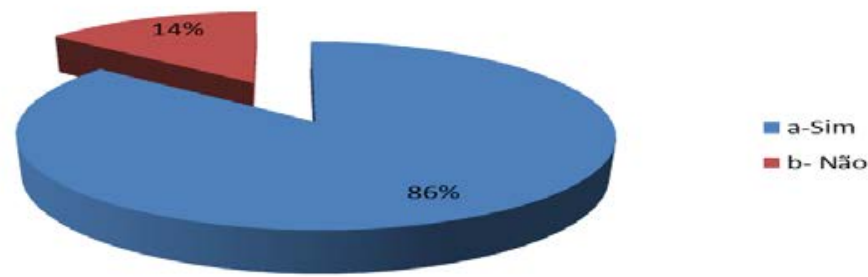

Fonte: A própria pesquisa.

Gráfico 3: aponta que $86 \%$ dos professores, concordam que que a formação continuada contribui positivamente quanto ao desenvolvimento da capacidade de liderança nas formações continuadas. No entanto, 14\% disseram que não contribui de forma positiva.

Gráfico 4: Quanto o favorecimento para a aplicação de procedimentos significativos?

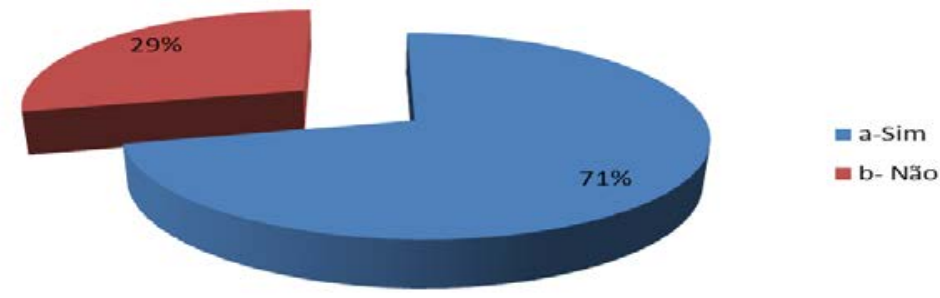

Fonte: A própria pesquisa. 
No gráfico 4: 71\% dos docentes responderam que a formação continuada propicia 0 favorecimento para a aplicação de procedimentos significativos. No entanto, $29 \%$ disseram que nem todos os procedimento são significativos, pois não condizem com a realidade do aluno.

Quadro 1: complementar sobre a formação continuada aos docentes.

\begin{tabular}{|c|c|}
\hline Aspectos investigados & Dados coletados/ Professores \\
\hline 5) Melhor inter-relação; & $\begin{array}{l}100 \% \text { dos docentes responderam que a } \\
\text { formação continuada, melhora a inter- } \\
\text { relação. }\end{array}$ \\
\hline 6) Criatividade expandida; & $\begin{array}{l}100 \% \text { dos docentes responderam que a } \\
\text { formação continuada contribui de forma } \\
\text { positiva na criatividade do docente. }\end{array}$ \\
\hline $\begin{array}{l}\text { 7) Concretização dos valores éticos e } \\
\text { morais; }\end{array}$ & $\begin{array}{l}100 \% \text { dos docentes, concordam que a } \\
\text { formação continuada contribui nas questões } \\
\text { éticos e morais }\end{array}$ \\
\hline 8) Melhor desenvolvimento profissional; & $\begin{array}{l}100 \% \text { dos docentes respondem que a } \\
\text { formação continuada, contribui de forma } \\
\text { relevante no desenvolvimento profissional. }\end{array}$ \\
\hline $\begin{array}{l}\text { 9) Motivação e entusiasmo para o } \\
\text { trabalho; }\end{array}$ & $\begin{array}{l}100 \% \text { dos docentes disseram que a cada } \\
\text { formação continuada, contribui para a } \\
\text { motivação e o entusiasmo profissional. }\end{array}$ \\
\hline 10) Desenvolvimento de potencialidades; & $\begin{array}{l}100 \% \text { dos docentes disseram que acreditam } \\
\text { que a formação contínua para o professor, } \\
\text { contribui para o desenvolvimento do } \\
\text { potencial docente. }\end{array}$ \\
\hline 11) Corresponsabilidade; & $\begin{array}{l}100 \% \text { dos docentes, responderam que a } \\
\text { formação continuada, contribui para } \\
\text { corresponsabilidade docente, }\end{array}$ \\
\hline 12) Solidariedade; & $\begin{array}{l}100 \% \text { dos docentes colocaram que a } \\
\text { formação continuada propicia o } \\
\text { favorecimento da solidariedade. }\end{array}$ \\
\hline
\end{tabular}

Fonte: A própria Pesquisa.

Esta coleta de dados ocorreu durante o segundo semestre letivo do ano de 2017, com professores, de uma Escola Rural, docentes participantes do curso PNAIC, ofertado pelo Ministério de Educação e Cultura.

Pode se perceber que a formação continuada reflete de forma positiva na prática do docente para a prática em sala de aula, conforme quadro demonstrativo, explicitando as respostas dos participantes.

\section{5.-Conclusão.}

Percebeu-se que o desafio que permeia a gestão escolar não é apenas, uma recuperação do saber acumulado em torno da formação com sentido, mas também uma resposta à crise atual da educação. 
Entretanto, a crise pode ser resumida no fato de muitos alunos resistirem diante da forma como thes ensinam nas salas de aula e nas escolas. Por outro lado a pesquisa mostra que os docentes estão dispostos a aprender outro modo de ensinar, diferente daquele que sempre utilizaram.

Assim sendo, hoje, mais que nunca, o docente precisa estar em constante aquisição de conhecimento revendo o que constitui de fundamental na sua prática pedagógica, e criar, novos mecanismos de conhecer e se relacionar com o conhecimento e com 0 aluno.

Enfim, supõe-se ir além dos limites do que parece aceitável para que se possa repensar e transgredir, produzir narrativas e experiências de aprendizagem com sentido, contribuindo dessa forma para a melhora na qualidade da educação, e na vida profissional do docente.

\section{6.-Referências.}

Barbieri, M.R., Carvalho, C.P., Ulhe, Á.B. (1995). Formação continuada dos profissionais de ensino. Cadernos Cedes, n.36.

Candau, V.M. (2001). Universidade e formação de professores: Que rumos tomar? Magistério. Construção cotidiana. Petrópolis: Vozes.

Cortela, M.S. (2002). A escola e o conhecimento: fundamentos epistemológicos e políticos. São Paulo: Cortez.

Demo, P. (1993). Desafios modernos da educação. Rio de Janeiro: Vozes.

Freire, P. (1979). Educação e mudança. Rio de Janeiro: Paz e Terra.

Lima, M.S.L. (2003). A formação contínua do professor nos caminhos e descaminhos do desenvolvimento profissional. São Paulo: PUCSP.

Morim, E. (2005). Os sete saberes necessários à educação do futuro. $10^{\mathrm{a}}$ ed. São Paulo: Cortez.

Perrenoud, F. (2000). Dez novas competências para ensinar. Porto Alegre: Artmed.

Sacristán, J.G. (1998). Compreender e transformar o ensino? Sacristán, J.G e Gomez, P.A.I. trad. Fonseca, E.F.R. 4aed. Porto Alegre: Artmed.

Shor. (1986). Ira, medo e ousadia, o cotidiano do professor. Rio de Janeiro: Terra.

Wachowicz, L.A. (1989). O método dialético na didática. Campinas: Papirus. 